\title{
Tribological Properties of Ni-P Electroless Coatings on Low- Carbon Steel Substrates Using an Environmentally Friendly Pretreatment
}

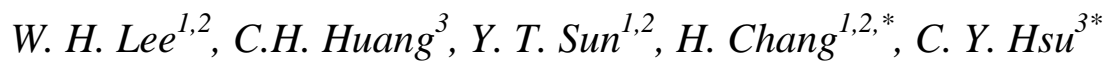 \\ ${ }^{1}$ Graduate Institute of Manufacturing Technology, National Taipei University of Technology, Taipei, \\ Taiwan \\ ${ }^{2}$ Department of Mechanical Engineering, National Taipei University of Technology, Taipei 10608, \\ Taiwan \\ ${ }^{3}$ Department of Mechanical Engineering, Lunghwa University of Science and Technology, Taoyuan \\ 33306, Taiwan \\ *E-mail: f10381@ ntut.edu.tw, cyhsu@mail.lhu.edu.tw
}

doi: $10.20964 / 2018.02 .64$

Received: 18 August 2017 / Accepted: 25 October 2017 / Published: 28 December 2017

This study deposits Ni-P alloy films coatings onto low carbon steel substrates using an electroless process. The coating's morphology and properties, including the hardness, polarization and frictional behavior, are analyzed. A conventional pretreatment that uses roughening and activation steps ensures better adhesion between the Ni-P plated layer and the substrate and renders the substrates catalytic. This study reports an environmentally friendly pretreatment for the substrates: physical sandblasting (using emery powder particles) and oxygen plasma etching. XRD analysis shows that the diffraction pattern for the Ni-P alloy exhibits a wider peak, which indicates that there is an amorphous phase. SEM micrographs after electroless Ni-P plating that uses plasma etching show that the surface is more even and fairly smooth, which indicates good Ni-P film characteristics. The experimental results show that a plasma etching pretreatment for coating with $\mathrm{Ni}-\mathrm{P}$ film increases the hardness and corrosion resistance and reduces the coefficient of friction.

Keywords: electroless plating, substrates pretreatment, Ni-P films, sandblasting, plasma etching.

\section{$\underline{\text { FULL TEXT }}$}

(C) 2018 The Authors. Published by ESG (www.electrochemsci.org). This article is an open access article distributed under the terms and conditions of the Creative Commons Attribution license (http://creativecommons.org/licenses/by/4.0/). 